\title{
Bringing method to the madness: An example of integrating social science qualitative research methods into NVivo data analysis software training \\ Mandy Swygart-Hobaugh ${ }^{1}$
}

\section{Abstract}

It is not uncommon for researchers who wish to delve into qualitative data analysis to be lacking in qualitative methods training. Data professionals who support these aspiring qualitative researchers are well positioned to recognize and develop resources, training, and services to address this methods gap. This article describes a specific training session aimed at bridging this gap: a collaboration between a sociology professor and the author that integrates a qualitative methodological framework with specific features of NVivo qualitative data analysis software that complement and facilitate research guided by that framework. This article (1) outlines how this collaboration came to be; (2) describes the roles that the sociology professor and the author play in the collaboration, including specific examples from the training session; and (3) offers a reflection on the experience, including successes and growth possibilities going forward.

\section{Keywords}

qualitative research, qualitative data analysis, theorizing, NVivo qualitative data analysis software, data services workshops, data services support and training

\section{Introduction}

I want to bring us to that awesome point where you have collected the closetsfull [sic] or tons of data and then you have to do something with them. You face the terrible moment when you want to leave this mortal coil because you are wondering what all of this awful buzzing confusion called "the data" can possibly mean. ... What is the story? What is in there?

In the summer of 2017, I and two other members of IASSIST's Qualitative Social Science and Humanities Data Interest Group co-authored a four-post series for IASSIST's iBlog discussing how data-support professionals can assist researchers who wish to delve into qualitative research but are lacking in methodological training - what we referred to as the 'qualitative methods gap' (Swygart-Hobaugh et al., 2017). In the third post of the series, I highlighted how data-support professionals 'can draw on their own expertise and also partner with qualitative researchers on campus to offer presentations, workshops, brown bags, etc., aimed at addressing the qualitative methods gap' (Swygart-Hobaugh, 2017). I cited a specific example of this type of collaboration: a training session given by a sociology professor and me that bridges a qualitative methodological framework with specific features of NVivo qualitative data analysis software. This article (1) outlines how this collaboration came to be; (2) describes the roles that the sociology professor and I play in the collaboration, including specific examples from the training 
session; and (3) offers a reflection on the experience, including successes and growth possibilities going forward.

\section{The Birth of a Collaboration}

In August 2014 at the invitation of QSR International, the company that makes NVivo, I created and delivered the webinar, 'Using NVivo 10 for Windows for Sociological Qualitative Data Analysis' (SwygartHobaugh, 2014). Unbeknownst to me, Dr. Ralph LaRossa, a Georgia State University Emeritus Professor of Sociology, was in attendance. Dr. LaRossa has written a number of articles advancing qualitative methodological inquiry. We had previously conversed about the pros and cons of using computer assisted/aided qualitative data analysis software (CAQDAS), such as NVivo, Atlas.ti., Dedoose, etc., at which time he had yet to take the plunge into using CAQDAS.

Dr. LaRossa emailed me to ask whether I concurred that certain aspects of NVivo I had discussed in my webinar lent themselves to advancing a particular methodological framework that he had presented in previous publications and has continued to develop (LaRossa, 2005, 2012a, 2012b). His 'levels of theorizing in qualitative analysis' framework (LaRossa, 2012b: 649-654), which I will discuss in more detail later in this article, delineates a model for moving qualitative research beyond description into hypothesis and relationship explorations. After reading his articles, I replied that I wholeheartedly concurred that his framework readily linked to the NVivo features I had presented, and that I saw potential for even more NVivo features realizing his methodological framework. I also mentioned that during one-on-one consults and workshops, I sometimes witnessed a paucity of qualitative methods knowledge among aspiring NVivo users, and that I planned to share his articles with campus researchers as a possible framework that might demystify the process of qualitative data analysis. I then proposed that we do a joint presentation: he presenting his methods for qualitative research, and I presenting the mechanics of using NVivo to implement his methods. He replied that he was indeed interested; various meetings and discussions ensued to develop our joint presentation, with the aim of debuting it that following spring semester.

\section{Interweaving the Logics (Qualitative Method) into the Logistics (NVivo Mechanics)}

The following is the title and synopsis of our joint presentation as described in the event posting and promotional communications:

\section{The Logics and Logistics of Qualitative Research: A Framework for Exploring Concepts, Dimensions, and Relationships in Qualitative Data using NVivo Research Software}

In this presentation, Dr. Ralph LaRossa, Professor Emeritus of Sociology, and Dr. Mandy SwygartHobaugh, Librarian Associate Professor for Sociology \& Data Services and Team Leader for Research Data Services, present both the theoretical-methodological logics and the appliedmethodological logistics of conducting qualitative data analysis (i.e., non-statistical analysis of textual, audio, visual, and/or audiovisual sources). Dr. LaRossa discusses the steps involved in building theoretically-rich qualitative analyses (the logics). Dr. Swygart-Hobaugh outlines the specific features of NVivo qualitative research software that complement and facilitate these analyses (the logistics).

Our first iteration was presented in March 2015, and we have given the presentation four subsequent times (in October of 2015, 2016, 2017, and 2018), continuously revising toward improvement and to incorporate changes with newer NVivo versions (cycling from version 10 to 11 Pro to the current 12 Plus

2/16 Swygart-Hobaugh, Mandy (2019) Bringing method to the madness: An example of integrating social science qualitative research methods into NVivo data analysis software training, IASSIST Quarterly 43(2), pp. 1-16. DOI: https://doi.org/10.29173/iq956 
version). Attendees span the various social sciences plus fields such as business, nursing, and public health. While attendees were predominantly Georgia State University affiliates, researchers from other metro Atlanta universities, non-profit organizations, and government agencies have attended as well.

The presentation is 90-minutes in length, delivered via PowerPoint slides, and divided into three parts: (1) a lecture by Dr. LaRossa on his methodological framework, (2) a demonstration by me of relevant NVivo features via screenshots, and (3) question and answer time. Attendees receive a handout with our contact information, a list of the readings cited in the presentation, and a link to my NVivo online help guide that includes information about upcoming hands-on NVivo workshops (Appendix 1).

While Dr. LaRossa draws from several of his own publications and those of others in his lecture, he primarily focuses on explicating his 'levels of theorizing in qualitative analysis' framework (LaRossa, 2012b: 649-654). I have crafted my portion of the presentation to demonstrate specific NVivo features that facilitate the framework that he presents. Dr. LaRossa uses examples from his own research on adviceseeking letter exchanges between parents and the educator and author Dr. Angelo Patri between the mid1920s to the late 1930s (LaRossa and Reitzes, 1993). This dataset consists of approximately 900 letter exchanges in text format and is available from the ICPSR data repository (LaRossa, 2009). I downloaded and imported the letter exchanges into NVivo to use for my demonstration slides in order to make direct connections between examples given in our respective parts of the presentation. ${ }^{3}$

\section{LaRossa's Framework: Levels of Theorizing in Qualitative Analysis}

This section of the article contains a summary of Dr. LaRossa's overall framework and then three subsections that correspond to the three 'levels of theorizing' he proposes. In each subsection, I briefly summarize his conception of the level and how he presents it in our joint presentation, and then I demonstrate how I tie aspects of the level to specific NVivo features in my portion of the presentation.

Drawing from his years of experience as a reviewer and as Deputy Editor for the Journal of Marriage and Family, LaRossa proposes that qualitative research generally operates along three dimensions:

... [W]e can visualize a world in which every qualitative manuscript can be plotted by its latitude (where it is with respect to the humanities and sciences), longitude (where it is with respect to the length and number of data excerpts), and altitude (where it is with respect to the level of theorizing). (2012b: 644-645)

The 'altitude' dimension is where LaRossa expands on his 'levels of theorizing' framework. In his conceptualization, 'theorizing' relates to whether a qualitative manuscript should 'be essentially descriptive, with a set of concepts and/or variables presented but with not much said about the possible relationships among those concepts and/or variables,' or whether it should move to 'a higher level of abstraction, talk about variable relationships and make, as its centerpiece, the development of hypotheses' (LaRossa, 2012b: 648). He then demarcates qualitative analysis theorizing into three levels, including a diagram reminiscent of three stair steps to illustrate the upward movement to higher levels of theorizing (LaRossa, 2012b: 650, Figure 4).

\subsection{Level 1: Concept Formation - Denoting and Connoting}

As conceptualized by LaRossa, at Level 1 a qualitative researcher 'denotes' text segments (in manual coding, by underlining them with a pencil, or highlighting them with a marker, etc.) 'with the purpose of

3/16 Swygart-Hobaugh, Mandy (2019) Bringing method to the madness: An example of integrating social science qualitative research methods into NVivo data analysis software training, IASSIST Quarterly 43(2), pp. 1-16. DOI: https://doi.org/10.29173/iq956 
singling out text segments that are thought to be important' and then 'connotes' the denoted text segments by 'linking' them with an analytical concept to which that segment speaks or resonates (LaRossa, 2012b: 649). The demarcated text segments are 'indicators' in grounded theory methods terminology (LaRossa, 2005). LaRossa (2005) argues that when engaging in concept-indicator formation - more broadly termed coding - researchers move along the dialectic path between deduction (their analytical framework and/or research questions inform their gleaning of concept-indicator connections) and induction (they let concept-indicator connections emerge from the data without being fettered by preconceived assumptions/frameworks/research questions). Level 1 theorizing (concept-indicator coding) can be understood as the foundation of all qualitative data analysis.

In his presentation of Level 1, Dr. LaRossa offers examples of denoting and connoting drawn from his own research on the Patri letter exchanges. He uses a figure (LaRossa, 2012b: 650, Figure 3) to illustrate how an individual text segment can be denoted (underlined) and then connoted at multiple concepts, be they (1) a priori, from an existing, recognized theory/framework, (2) in vivo, reflecting verbatim the text in the analyzed materials, or (3) juxta vivo, a middle-ground between a priori and in vivo.

To demonstrate to researchers the utility of qualitative research software for Level 1 theorizing, I first present coding using NVivo nodes as a means for researchers to engage in denoting and connoting (Figure 1).

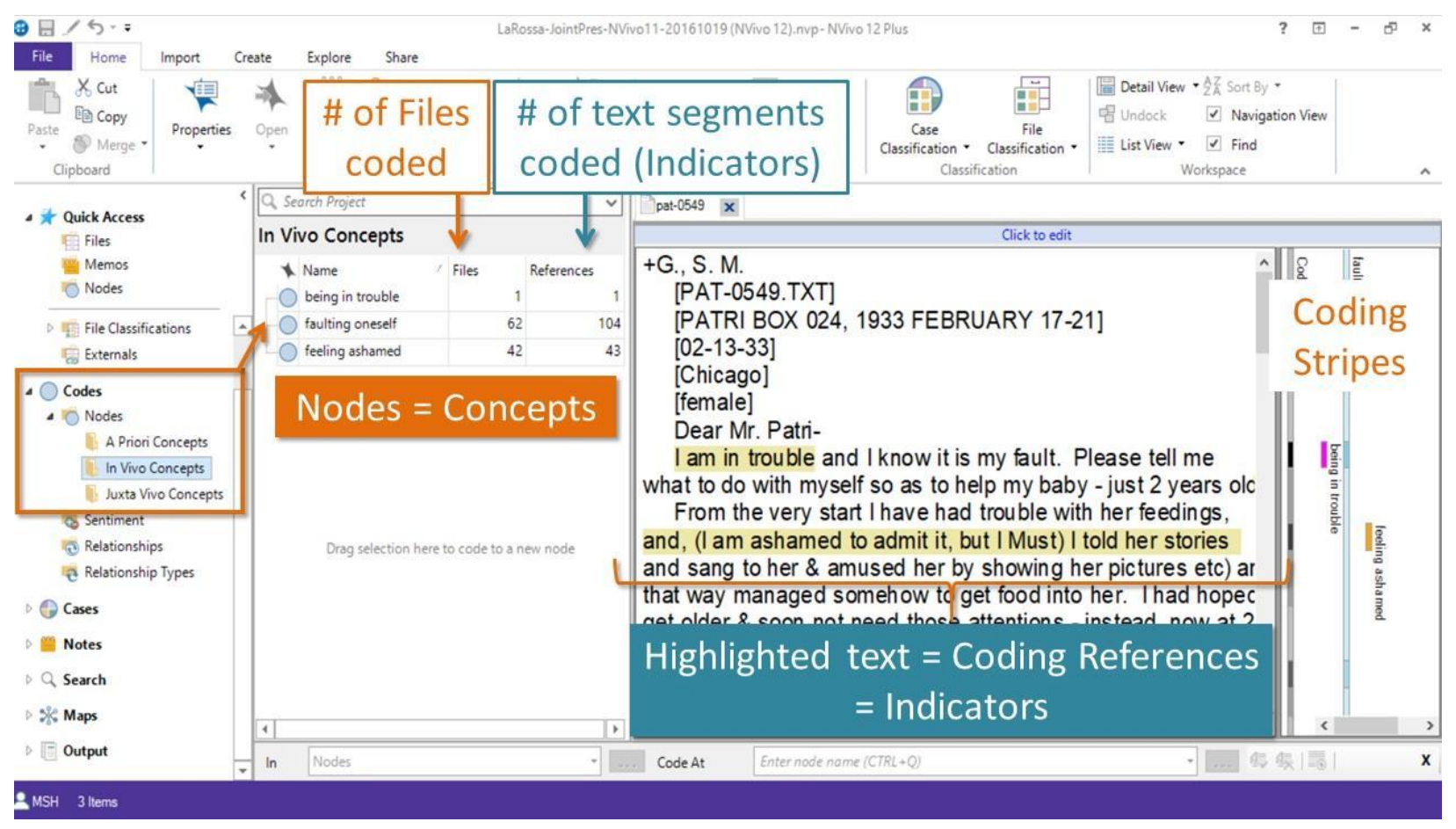

Figure 1: Using NVivo nodes to denote and connote (or code) text.

I present nodes as akin to concepts and coded text segments (or NVivo coding references) as akin to indicators as described by Dr. LaRossa. I explain that the basic mechanics of coding in NVivo entails first highlighting the text segment (denoting it as an indicator), then right-clicking it to then either code it at an existing node or a new node (connoting it at an existing or new concept). I also note that in software such as NVivo you can readily code a single text segment/indicator at multiple concepts if it is analytically

4/16 Swygart-Hobaugh, Mandy (2019) Bringing method to the madness: An example of integrating social science qualitative research methods into NVivo data analysis software training, IASSIST Quarterly 43(2), pp. 1-16. DOI: $\underline{\text { https://doi.org/10.29173/iq956 }}$ 
warranted - a task that proves more challenging when doing manual coding. For example, in the letter pictured in Figure 1 above, the mother in her opening sentence writes, 'I am in trouble and I know it is my fault'. The researcher can denote that sentence by highlighting it, then connote it by right-clicking the highlighted text segment and check-boxing the existing nodes of 'faulting oneself' and 'being in trouble'.

I also describe how you can double-click on a node to then easily access data files and the corresponding text segments coded within data files at that node and other nodes (by using the NVivo coding stripes feature), which allows the researcher to easily move through their data and see similarities/differences of concepts across the different data files that would, again, prove more challenging when coding manually. For example, looking again at the Figure 1 screenshot above, the researcher can double-click the 'faulting oneself' node to see a listing of the 104 individual text segments/references coded at that node parsed by the 62 letters/files in which those text segments appear, which will allow the researcher to delve into the nuances of how that concept emerges in the letters and how it diverges/converges between and within letters. I also point out the utility of NVivo tallying the number of coding references (text segments/indicators) coded at a node, as a researcher can cite these counts to argue that a node/concept with 'numerous indicators [is] theoretically saturated' (LaRossa, 2005: 846).

I next discuss how researchers can use NVivo queries to tease out possible concept-indicator connections. For example, I demonstrate a word frequency query that returns the top 25 most frequently occurring words and their stemmed variations across the Patri letter exchanges (Figure 2).

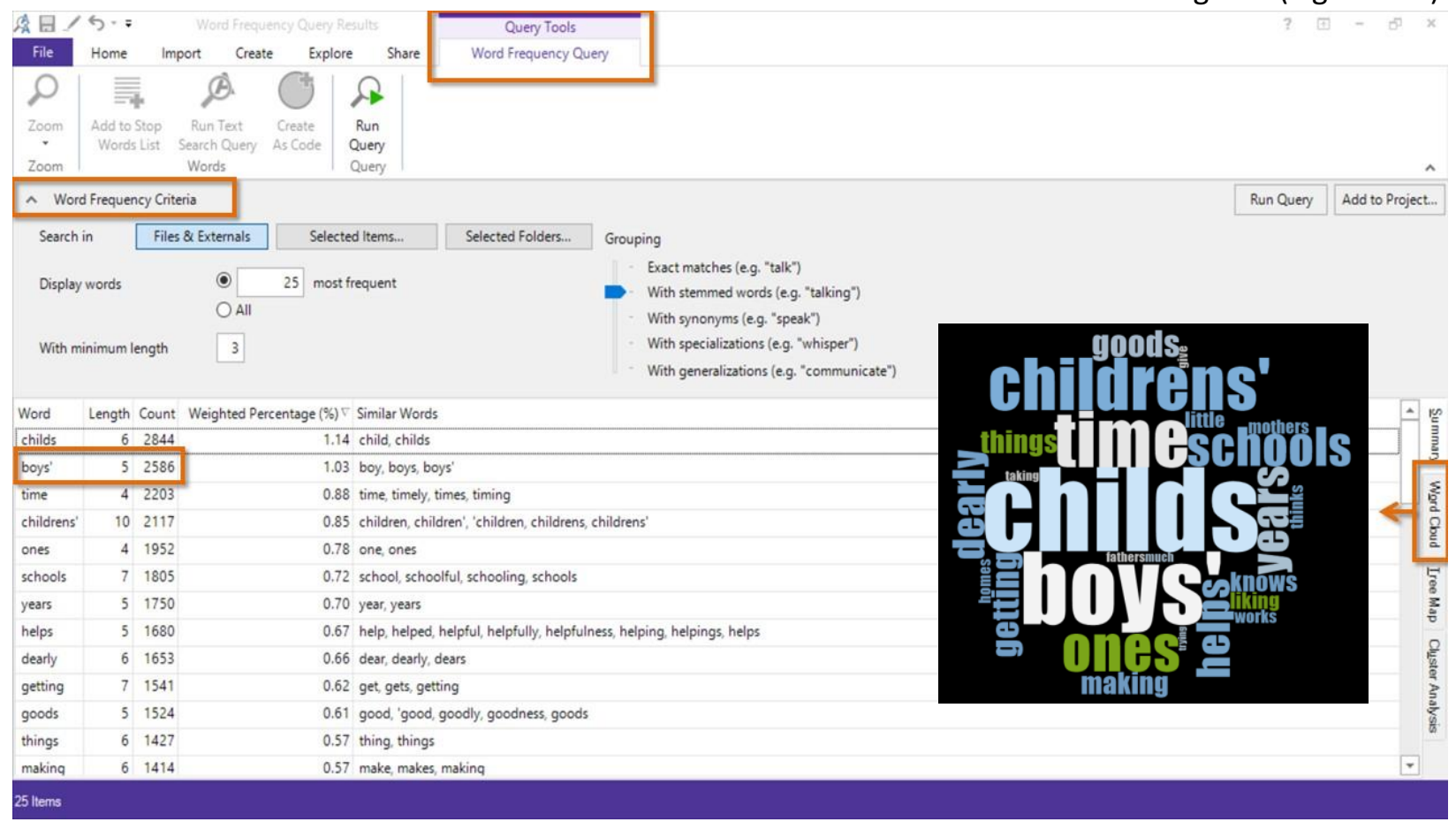

Figure 2: Using an NVivo word frequency query to explore potential concept-indicator connections. 
I note that it grabbed my attention that boy/boys/boys' is the second most frequently occurring word, while girl/girls/girls' does not even make the top 25. I show how I can double-click on boys in the word frequency list to jump to a page that parses out the occurrence of the word across the data files, showing boy/boys/boys' with the five preceding words and the five succeeding words to give brief context for its use but allowing me to click on a hot-linked data file name to jump to that specific file and see the word used in its full context. I then pose the following analytical questions we might explore:

What interpretations might we draw from boy/boys being the second most frequent word grouping, appearing 2586 times, and girl/girls not even making the top 25? Is there something about the discussion of boys (and, by association, girls) that alludes to a concept-indicator connection we could code for? Does it point to the possibility that the gender of the child plays a critical role in the data? Are boys perceived as more trouble (thus necessitating more advice seeking regarding their rearing)? Are boys held as more important than girls and thus more worthy of seeking advice about? What story might we tell with this finding if we dig deeper?

For my last example of Level 1 theorizing I demonstrate how a researcher can use a text search query to explore possible connections between searched words and a concept - i.e., to explore possible conceptindicator connections (Figure 3).

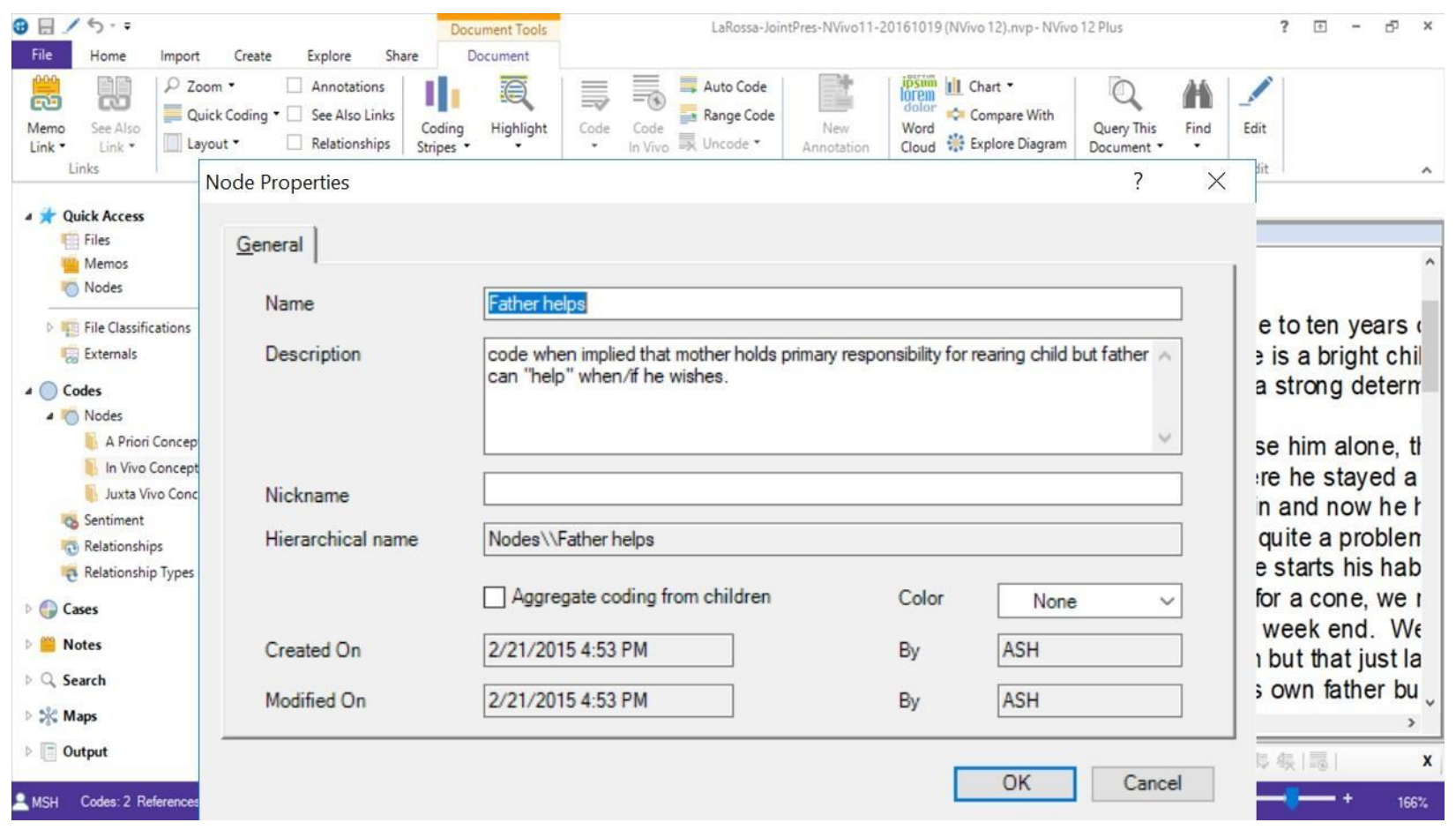

Figure 3: Using an NVivo text search query to explore potential concept-indicator connections.

For example, I might be curious about how the word 'help' and similar words are used in the Patri letter exchanges. I can do a text search query across the data files using a Boolean logic search for help OR aid OR assist (and their stemmed variations) to drill down to instances of these words in the letter exchanges. Then I can explore whether the word usage indicates a concept I should create and code for in the letters. For example, I might create a concept node called 'Father helps' and code text segments at this node 
when it is implied that mothers hold primary responsibility for rearing children, but fathers can 'help' when/if they choose.

\subsection{Level 2: Variable Formation - Dimensionalizing}

In his article and in his part of our joint presentation, LaRossa (2012b) proposes that qualitative researchers move to Level 2 theorizing when they bring variables or dimensions of concepts into their consideration and analysis of the data. Returning to his own research on the Patri letter exchanges, Dr. LaRossa shows how the in vivo concept of 'faulting oneself' for the trouble a mother has feeding her baby becomes a variable/dimension when the researcher begins to array possibilities within the larger concept, such as 'extent of faulting oneself' or 'blame taking (yes or no)' (LaRossa, 2012b: 653, Figure 4). He also mentions how qualitative researchers can incorporate relevant variables into their analysis such as age and marital status (LaRossa, 2012b). For example, my proposing that the child's gender might have some bearing on a parent seeking child-rearing advice from Patri illustrates that, even while at the first level of theorizing, I was already moving toward Level 2 variable/dimension formation by injecting gender-of-child as a variable.

In my presentation of using NVivo for Level 2 variable/dimension formation, I begin with demonstrating how researchers can create hierarchical node structures (what NVivo calls parent nodes and child nodes) to represent variability/dimensions of a concept (Figure 4).

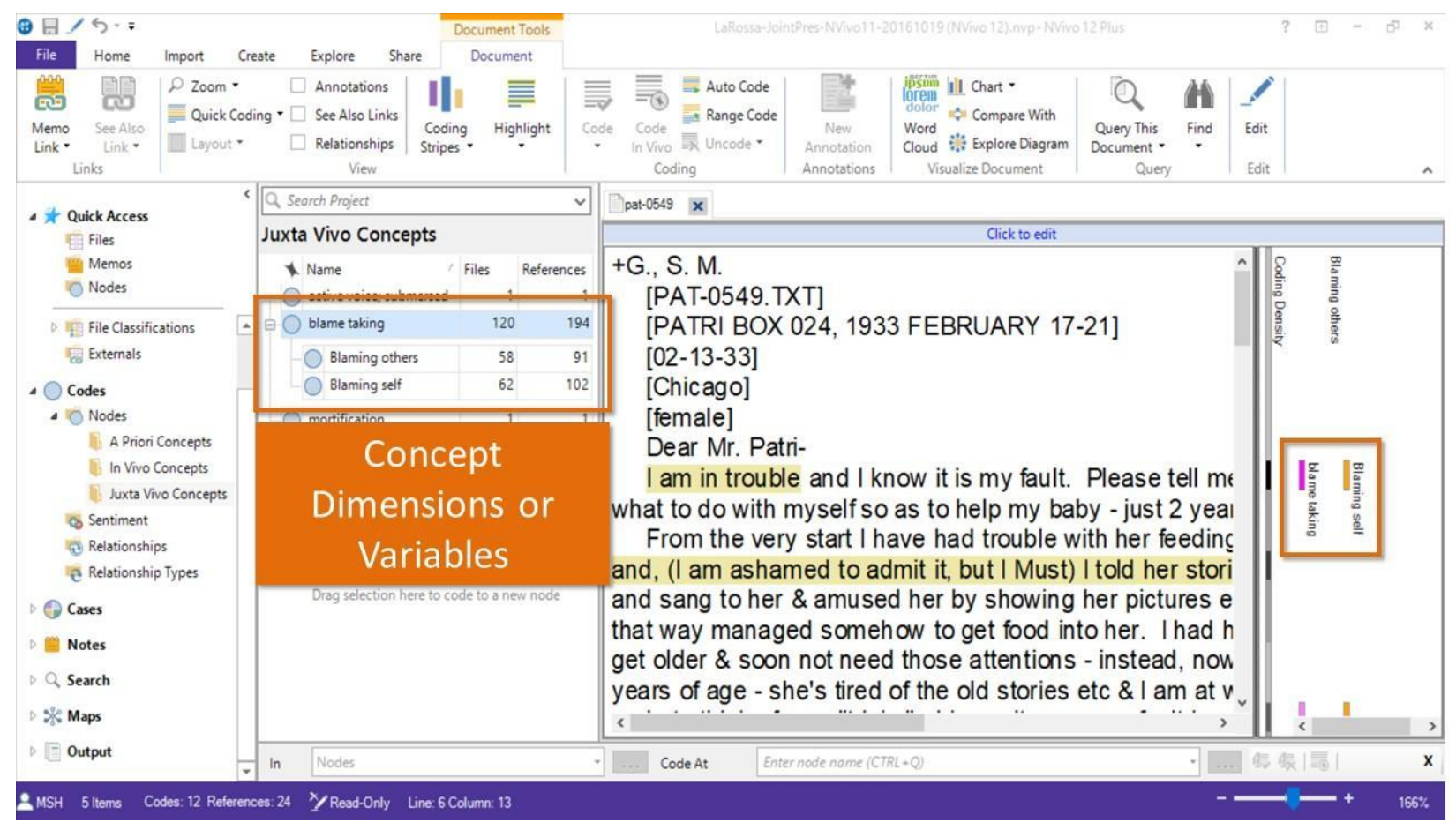

Figure 4: Creating NVivo parent and child node hierarchies to code for variables/dimensions.

For example, I created a parent node for the concept of 'blame taking' and created child nodes of 'blaming others' and 'blaming self' as dimensions of that concept. If analytically warranted, I could create deeper node hierarchies to represent dimensions within the child nodes (e.g., under 'blaming others' I might add child nodes of 'blaming spouse' or 'blaming child' or 'blaming in-laws', etc.). I discuss the option of 
aggregating coding from child nodes, which allows the researcher to code at a child node but then have the coding automatically applied to the parent node (or grandparent node and on up, if applicable). I also highlight NVivo's flexibility and ease of renaming, rearranging, and merging nodes within and across hierarchies when analytically warranted - a process of 'fractur[ing]' or 'reconstitut[ing]' concepts that is important in grounded theory methods (LaRossa, 2005: 846).

I next discuss NVivo's classification sheet feature as a means to define variations in attributes (akin to variables) about the units of analysis, which then can be used for analytical comparisons and/or variablerelationship formation (the next level of theorizing in LaRossa's framework). I display a screenshot of an NVivo classification sheet I created to classify attributes about the Patri letter exchanges (Figure 5).

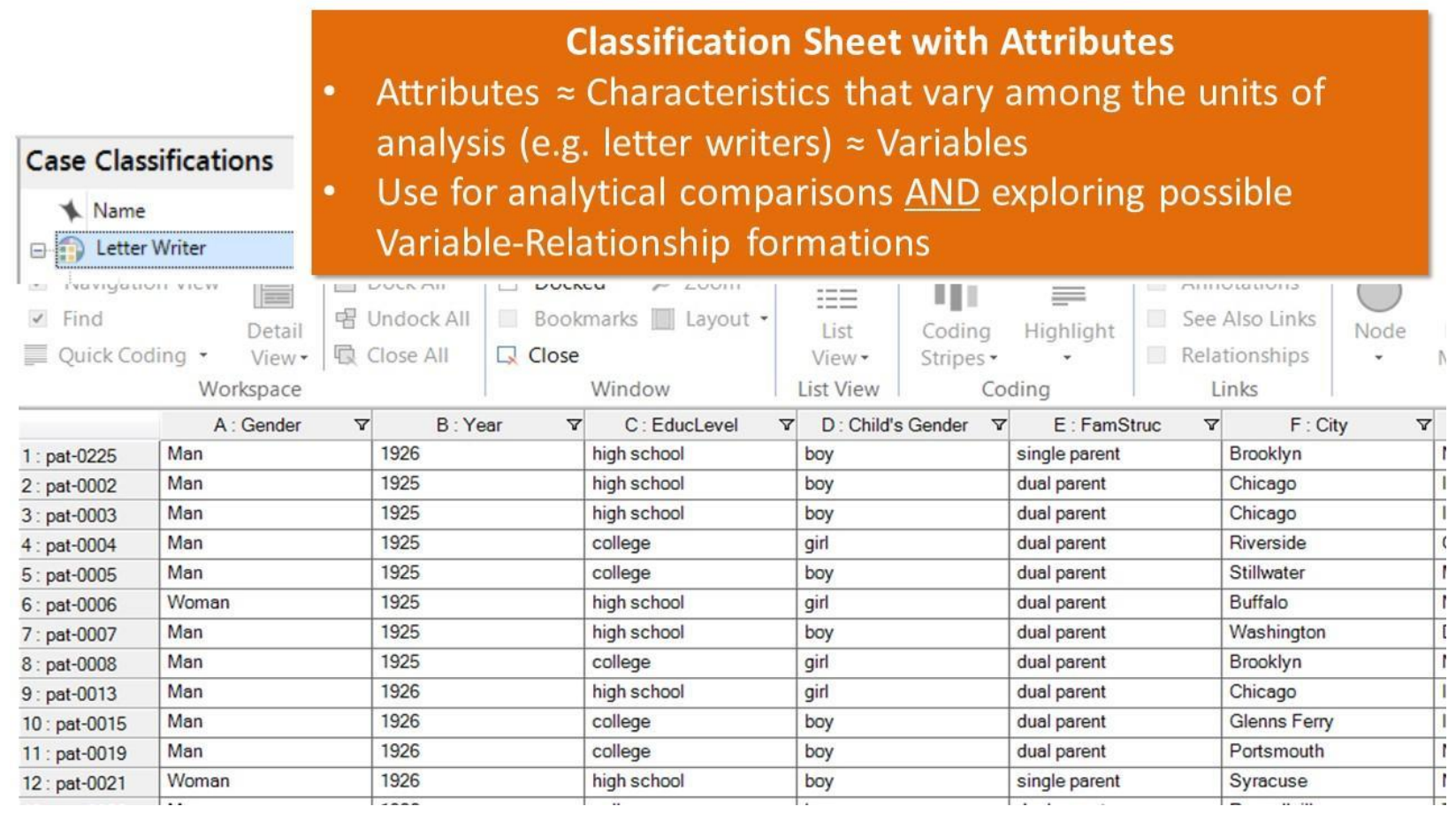

Figure 5: Using NVivo classification sheets to define attributes/variables for data units.

I explain that, similar to an SPSS statistical file, the rows of an NVivo classification sheet represent the individual data units (e.g., a Patri letter exchange data file), and the columns contain attribute/variable data that has been collected and compiled for the corresponding individual data units (e.g., gender of the letter writer, year of the letter, where the letter writer lived within the United States, the gender of the child discussed in the letter, etc.). ${ }^{4}$

\subsection{Level 3: Variable-Relationship Formation - Typologizing and Hypothesizing}

Dr. LaRossa in his article (2012b) and his part of our joint presentation describes Level 3 of his framework as the level at which qualitative researchers explore relationships between the variables and/or dimensions they developed at previous levels. LaRossa (2012b) argues that this variable-relationship formation takes two forms: typologizing and hypothesizing. When typologizing, 'two or more variables are cross-listed to create a matrix of cells' (LaRossa, 2012b: 653), which allows the researcher to explore the relationship of different variables/dimensions by examining the intersections of their differing 
components. LaRossa posits hypothesizing (proposing correlations and/or cause-and-effect relationships between variables) as another aspect of higher-level theorizing in qualitative research, while recognizing that it is 'especially tricky in qualitative research' due to its traditional association with positivist/quantitative research epistemologies that many qualitative researchers approach with skepticism if not outright reject (2012b: 653). He poses that while many qualitative researchers are wary of hypothesis testing due to its adherence to positivist/quantitative tenets and assumptions, hypothesis development - 'offer[ing] "plausible suggestions" about-not definitive tests of-variable relationships' - is likely more palatable, and is readily attainable and desirable in order for qualitative researchers to move to Level 3 theorizing (LaRossa, 2012b: 654, see also LaRossa 2012a).

In his part of the presentation, Dr. LaRossa departs from the Patri letter exchanges to present the Level 3 variable-relationship formation paradigm, using examples from his other research endeavors (LaRossa and LaRossa, 1981; LaRossa and Sinha, 2006). I return to the Patri letter exchanges to offer several NVivo features that facilitate typologizing and hypothesizing to examine variable-relationship formation:

- Using crosstab queries and matrix coding queries to examine the intersections of variable/dimension components (typologizing) or to explore hypothesized relationships between variables/dimensions (hypothesizing)

- Using coding queries to examine when text segments have overlapping coded concepts to examine potential relationships between those concepts (e.g., is there a relationship between letter writers' faulting themselves and feeling ashamed?); creating and coding those text segments as a relationship (e.g., faulting oneself influences feeling ashamed); and creating a chart (under NVivo Explore menu) of the relationship broken down by a selected attribute's values to examine whether the attribute has a moderating influence on this relationship (e.g., is the faulting-oneself-influences-feeling-ashamed relationship more prevalent in women letterwriters over men letter-writers?)

- Using NVivo visualizations (under NVivo Explore menu) to explore potential relationships:

- Generating a cluster analysis diagram that clusters selected nodes/concepts together if they code many of the same files (e.g., explore whether files coded at the 'faulting oneself' node cluster by coding similarity with files coded at the 'being ashamed' node)

- Generating a comparison diagram of two nodes/concepts that visually displays what files they share and do not share in terms coding (e.g., which files are coded at both 'faulting oneself' and 'being ashamed' and which are coded at only one or the other of the concepts)

For the sake of brevity - and because I believe it to be the most clear-cut and powerful of the aforementioned examples - I will expound upon my demonstration of an NVivo crosstab query as a means for both typologizing and hypothesizing. In my presentation I return to the node/concept of 'blame taking' and its dimensions (child nodes) of 'blaming self' and 'blaming others' and pose this question:

Is there a relationship between the gender of letter writers and whether they are taking or assigning blame for a child's issues?

I propose that one way to examine the relationship of the gender-of-letter-writer variable (or attribute in NVivo lingo) with the 'blame taking' concept variable/dimension is to run a crosstab query (Figure 6).

9/16 Swygart-Hobaugh, Mandy (2019) Bringing method to the madness: An example of integrating social science qualitative research methods into NVivo data analysis software training, IASSIST Quarterly 43(2), pp. 1-16. DOI: https://doi.org/10.29173/iq956 


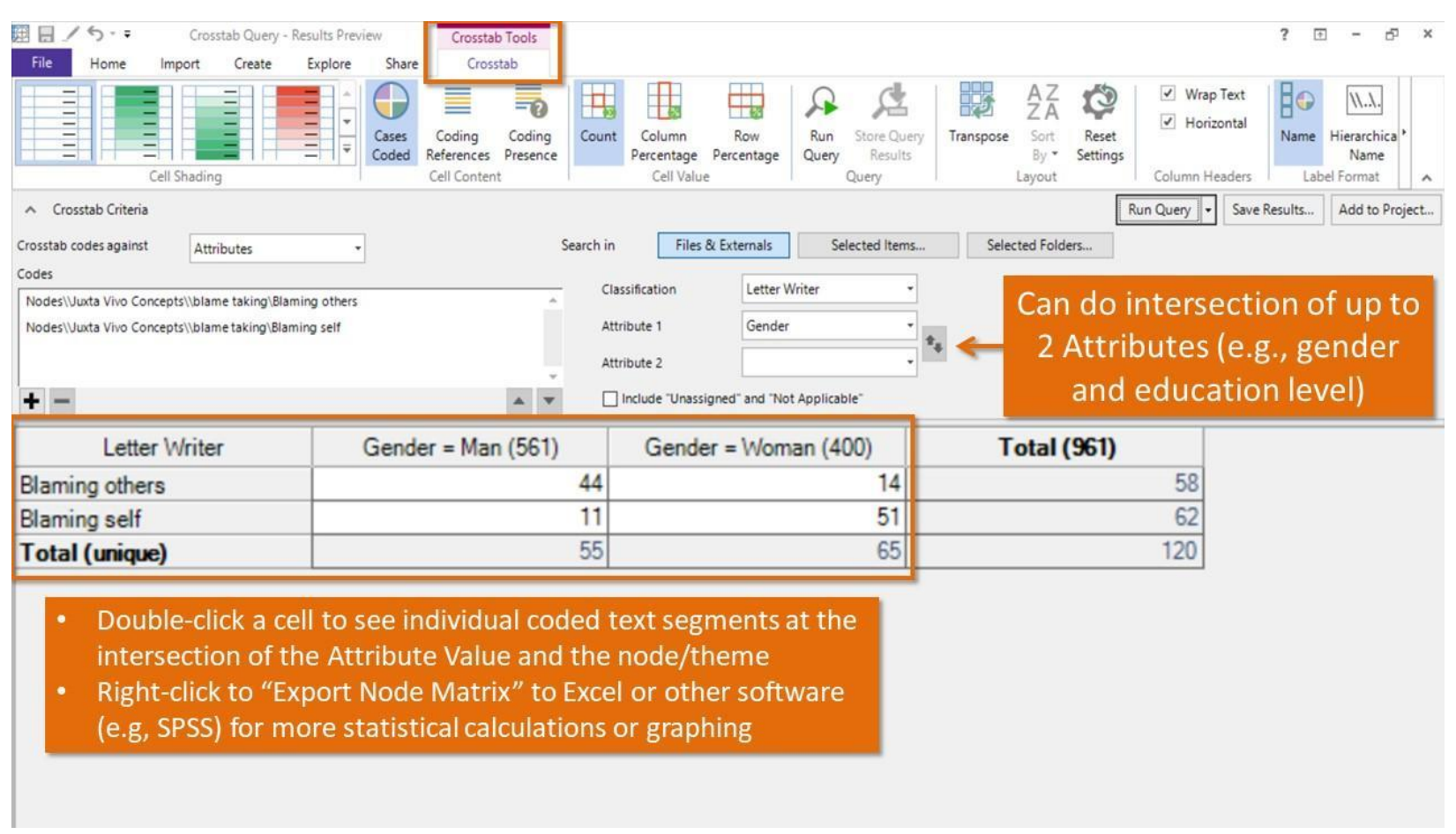

Figure 6: Using an NVivo crosstab query for variable-relationship formation.

I explain that the created crosstab matrix contains the two rows for the different dimensions of the 'blame taking' concept and two columns for the gender-of-letter-writer attribute values, and that the number displaying in each cell is the number of associated data files (letter exchanges) that have at least one text segment (indicator) coded at the associated 'blame taking' concept dimension (or child node). I stress that, rather than relying on these numbers alone for drawing conclusions (although they do in and of themselves give compelling evidence for a relationship), as qualitative researchers they should explore the coded text segments to delve deeper into, for example, variations in the language/themes used by men versus women when discussing blaming self or others - and accessing the associated text segments is easily achieved by just double-clicking the matrix cell. I then bridge this feature to Dr. LaRossa's typologizing and hypothesizing by presenting the following:

Out of the 55 men's letters with blaming discourse, 44 men's letters had one or more text segments coded to the 'blaming others' node, and only 11 had one or more text segments coded to the 'blaming self' node. In contrast, we see the reverse in the women's letters, with only 14 in the 'blaming others' cell and 51 in the 'blaming self' cell. Given this evidence, we might pose the following variable-relationship hypothesis: Among letter writers that engaged in blaming discourse, women were more likely to blame themselves than others, and men were more likely to blame others than themselves.

Throughout my demonstration, I continuously stress that NVivo does not do the intellectual work for the researcher, nor does any other qualitative data analysis software/tool. I tell them there is no magic button to push to have NVivo produce definitive findings. I stress that they still have to become intimately familiar with the data through reading and re-reading - i.e., as qualitative researchers committed to probing the rich, nuanced meaning within people's words, they should not just text mine and call that 'analysis'. I 
emphasize that NVivo is primarily a data management and organization tool that facilitates analysis - but the true analysis occurs within researchers' minds where they draw out the meaning from the data guided by their analytical and methodological frameworks and research questions.

\section{Reflections and Going Forward}

Overall, both Dr. LaRossa and I deem this collaboration a success. Verbal feedback from attendees is consistently positive, and we often hear from attendees that a colleague who had attended a previous iteration referred them. A comment in response to an evaluation question - 'What is the most useful thing you learned at the workshop?' - aptly resonates with the point of the session: I got a great rationale which can link theory to a practical research tool.

As there is always room for improvement, below are growth possibilities for future iterations:

- Gather more official feedback - while we distribute an online evaluation form to attendees after each presentation, we get very low response rate. One way to improve the response might be to hand out a short printed form instead and have attendees complete it before they leave.

- Increase turnout - although our registration is often full at 50 registrants (and with a waitlist), we average around $50 \%$ of registrants actually coming. While this low turnout rate is consistent with that of our other Research Data Services workshops, as the Leader of the Research Data Services Team I am working with my teammates on strategies to improve turnout.

- Consider adapting the NVivo portion of the joint session to be a live demonstration, and possibly hands-on - Using screenshots to demonstrate NVivo features proves efficient in terms of allowing coverage of more content in a shorter window, permitting visual annotations to facilitate understanding, and avoiding the risk of technological failures. That said, live demonstration and hands-on work would likely be more engaging for attendees and increase learning and retention of the NVivo mechanics presented. However, implementing live demonstration and/or hands-on activities would necessitate significantly more time for the session. Currently I encourage attendees to attend my upcoming hands-on NVivo workshops in which I cover many of the features presented. But, perhaps having a multi-part series (or maybe even a webinar series) could be warranted, wherein specific aspects of the levels-of-theorizing framework would be the entire focal point of each individual workshop. Weighing the pros/cons of our current delivery method against adding live/hands-on elements is something Dr. LaRossa and I could explore further.

After each offering Dr. LaRossa and I say to each other that we both learned more about qualitative methodology and qualitative data analysis software from the experience. In addition, our collaboration has bred collaboration outside of the presentation, often taking the form of "I saw this article and thought of your/our work" scenarios.

My work supporting qualitative researchers on the Georgia State University campus has unquestionably benefited from this experience. A key benefit of working closely with a widely published and respected methodologist on developing a method-embedded qualitative data analysis software training is that researchers get a clearer sense of how method should be the driving force behind their use of analysis software. My regularly offered workshops are primarily consumed by teaching the mechanics of using NVivo; as such, any integration of methods on my part is often tertiary or surface-level. This joint presentation with Dr. LaRossa allows me to articulate mindfully how method can, should, and must guide 
the use of the software's mechanics. Qualitative researchers wedded to manual coding often cite their fear that software such as NVivo, Atlas.ti, and Dedoose removes the researcher from the analysis process and 'does all the work' as their reason for shunning it. This joint presentation makes headway in alleviating these fears, as it demonstrates how qualitative data analysis software is merely a conduit via which the researcher applies their chosen theory and method - it is not the theory or method in and of itself. Similarly, aspiring qualitative researchers often learn method divorced from its application. This bridged method-mechanics training session offers a unique space to remove methods training from the vacuum in which it typically is taught.

In conclusion, I hope that this example experience of integrating qualitative research methods into qualitative data analysis software training can serve as a model, or at least an inspiration, for those who offer training and support for existing and aspiring qualitative researchers. If anything, it demonstrates that qualitative researchers are eager and grateful for knowledge and skills that help them bring method to the madness that is qualitative data.

\section{Acknowledgment}

I would like to thank Dr. Ralph LaRossa for his contributions to our joint presentation, his feedback on this article, and his continuing commitment to developing and teaching qualitative methodological inquiry that is rigorous, nuanced, and theoretically-rich yet still graspable.

\section{References}

LaRossa, R. 2005, "Grounded Theory Methods and Qualitative Family Research", Journal of Marriage and Family, vol. 67, no. 4, pp. 837-857, https://doi.org/10.1111/j.1741-3737.2005.00179.x.

LaRossa, R. 2009, Parenthood in Early Twentieth-Century America Project (PETCAP), 1900-1944, Ann Arbor, MI: Inter-university Consortium for Political and Social Research [distributor], Available at: https://doi.org/10.3886/ICPSR06876.v2.

LaRossa, R. 2012a, "Thinking About the Nature and Scope of Qualitative Research", Journal of Marriage and Family, vol. 74, no. 4, pp. 678-687, https://doi.org/10.1111/j.1741-3737.2012.00979.x.

LaRossa, R. 2012b, "Writing and Reviewing Manuscripts in the Multidimensional World of Qualitative Research", Journal of Marriage and Family, vol. 74, no. 4, pp. 643-659, https://doi.org/10.1111/j.1741-3737.2012.00978.x.

LaRossa, R. and LaRossa, M.M. 1981, Transition to Parenthood: How Infants Change Families, Sage Publications, Beverly Hills, CA.

LaRossa, R. and Reitzes, D.C. 1993, "Continuity and Change in Middle Class Fatherhood, 1925-1939: The Culture-Conduct Connection", Journal of Marriage and Family, vol. 55, no. 2, pp. 455-468, https://doi.org/10.2307/352815.

LaRossa, R. and Sinha, C.B. 2006, "Constructing the Transition to Parenthood", Sociological Inquiry, vol. 76, no. 4, pp. 433-457, https://doi.org/10.1111/j.1475-682X.2006.00165.x. 
Swygart-Hobaugh, M. 2014, Using NVivo 10 for Windows for Sociological Qualitative Data, available at https://www.youtube.com/watch?v=vfqaW6100rg (accessed 13 January 2019).

Swygart-Hobaugh, M. 2017, "But How Do I *Do* Qualitative Research? Bridging the Gap between Qualitative Researchers and Methods Resources--PART 3", in IASSIST iBlog, available from https://iassistdata.org/blog/how-do-i-do-qualitative-research-bridging-gap-between-qualitativeresearchers-and-methods-res-1 (accessed 12 January 2019).

Swygart-Hobaugh, M., Conte, J. and Cooper, L. 2017, "But How Do I *Do* Qualitative Research? Bridging the Gap between Qualitative Researchers and Methods Resources", in IASSIST iBlog, available from https://iassistdata.org/blog/how-do-i-do-qualitative-research-bridging-gap-betweenqualitative-researchers-and-methods-resou (accessed 12 January 2019). 


\section{Appendix 1}

Handout given to attendees at joint presentation.

\section{The Logics \& Logistics of Qualitative Research}

A Framework for Exploring Concepts, Dimensions, and Relationships in Qualitative Data using NVivo Research Software

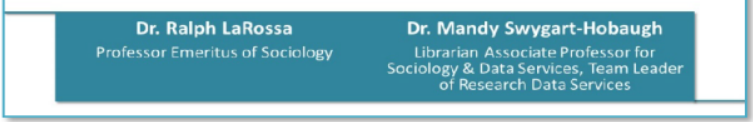

Further readings:
Thanks for attending this presentation!

\section{Feel free to contact the} presenters if desired:

Dr. Ralph LaRossa xxxxxx@gsu.edu

Dr. Mandy Swygart-Hobaugh xxxxxx@gsu.edu

- Abend, G., Petre, C., \& Sauder, M. (2013). Styles of causal thought: An empirical investigation. American Journal of Sociology, 119(3), 602-654. GSU access: http://bit.ly/1vGENJ9

- Davis, F. (1974). Stories and sociology. Urban Life and Culture 3(3), 310-316. GSU access: http://bit.ly/2wzAYNi

- LaRossa, R. (2012). Writing and reviewing manuscripts in the multidimensional world of qualitative research. Journal of Marriage and Family, 74(4), 643-659. GSU access: http://bit.ly/16NcbZ6

- LaRossa, R. (2012). Thinking about the nature and scope of qualitative research. Journal of Marriage and Family, 74(4), 678-687. GSU accss: http://bit.ly/17UISW1

- LaRossa, R. (2005). Grounded theory methods and qualitative family research. Journal of Marriage and Family, 67(4), 837-857. GSU access: http://bit.ly/1C16y12

- LaRossa, R., \& Sinha, C. (2006). Constructing the transition to parenthood. Sociological Inquiry, 76(4), 433-457. GSU access: http://bit.ly/1C56LTB

- LaRossa, R., \& LaRossa, M.M. (1981). Transition to parenthood: How infants change families. Beverly Hills, CA: Sage. GSU access: $\underline{\text { http://bit.ly/2xkYrge }}$

- Richardson, L. (1988). Secrecy and status: The social construction of forbidden relationships. American Sociological Review, 53(2), 209-219. GSU access: http://bit.ly/1z3CO1M

- Roy, K., Zvonkovic, A., Goldberg, A., Sharp, E., \& LaRossa, R. (2015). Sampling richness and qualitative integrity: Challenges for research with families. Journal of Marriage \& Family, 77(1), 243-260. GSU access: $\underline{\text { http://bit.ly/1KnVLEP }}$

NVivo online help guide - includes information about hands-on NVivo workshops being offered this semester:

\section{research.library.gsu.edu/nvivo}

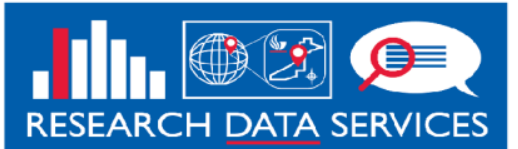

The Library's Research Data Services (RDS) Team offers support to GSU students, faculty, and staff in the areas of data analysis tools \& methods, mapping \& data visualization, finding data $\&$ statistics, survey design, RESEARCH DATA SERVICES and data management. Learn more at library.gsu.edu/data

LIBRARY.GSU.EDU/DATA 


\section{Appendix 2}

Selected readings on qualitative research methods and computer aided/assisted qualitative data analysis software (CAQDAS).

Bourdon, S. 2002, "The Integration of Qualitative Data Analysis Software in Research Strategies: Resistances and Possibilities", Forum Qualitative Sozialforschung / Forum: Qualitative Social Research, vol. 3, no. 2, doi: $10.17169 /$ fqs-3.2.850.

Houghton, C., Murphy, K., Meehan, B., et al. 2017, "From Screening to Synthesis: Using NVivo to Enhance Transparency in Qualitative Evidence Synthesis", Journal of Clinical Nursing, vol. 26, no. 5-6, pp. 873-881, doi: 10.1111/jocn.13443.

Hutchison, A.J., Johnston, L.H. and Breckon, J.D. 2010, "Using QSR-NVivo to Facilitate the Development of a Grounded Theory Project: An Account of a Worked Example", International Journal of Social Research Methodology, vol. 13, no. 4, pp. 283-302, doi: 10.1080/13645570902996301.

Leech, N.L. and Onwuegbuzie, A.J. 2011, "Beyond Constant Comparison Qualitative Data Analysis: Using NVivo", School Psychology Quarterly, vol. 26, no. 1, pp. 70-84, doi: 10.1037/a0022711.

Maher, C., Hadfield, M., Hutchings, M., et al. 2018, "Ensuring Rigor in Qualitative Data Analysis: A Design Research Approach to Coding Combining NVivo with Traditional Material Methods", International Journal of Qualitative Methods, vol. 17, no. 1, doi: 10.1177/1609406918786362.

Paulus, T., Woods, M., Atkins, D.P., et al. 2017, "The Discourse of QDAS: Reporting Practices of ATLAS.ti and NVivo Users with Implications for Best Practices", International Journal of Social Research Methodology, vol. 20, no. 1, pp. 35-47, doi: 10.1080/13645579.2015.1102454.

Woods, M., Paulus, T., Atkins, D.P., et al. 2016, "Advancing Qualitative Research Using Qualitative Data Analysis Software (QDAS)? Reviewing Potential Versus Practice in Published Studies using ATLAS.ti and NVivo, 1994-2013", Social Science Computer Review, vol. 34, no. 5, pp. 597-617, doi: $10.1177 / 0894439315596311$.

Zamawe, F.C. 2015, "The Implication of Using NVivo Software in Qualitative Data Analysis: EvidenceBased Reflections", Malawi Medical Journal, vol. 27, no. 1, pp. 13-15.

\section{Endnotes}

${ }^{1}$ Mandy Swygart-Hobaugh is the Leader of the Research Data Services Team at the Georgia State University Library, a data services librarian, and a liaison librarian for sociology. She can be reached by email: aswygarthobaugh@gsu.edu.

${ }^{2}$ Dr. LaRossa cites this quotation in his part of our joint presentation; it comes from the following: Davis $F$ (1974) Stories and Sociology. Urban Life and Culture 3(3): 310-316. DOI: $10.1177 / 089124167400300305$.

${ }^{3}$ Given I did not have the time to do actual analysis on the $900+$ letter exchanges, I artificially manipulated some of the analyses contained in my portion of the presentation to have ideal examples to illustrate NVivo's features. I inform the presentation attendees of this, and, of course, tell them that fabricating results is not accepted practice. I also tell them that the dataset is available via ICPSR if others wish to use the resources for actual analyses, but they should bear in mind that the data will not necessarily produce the results as presented. The word frequency 
query and text search query results presented are genuine; the remaining coding and analysis examples have been artificially manipulated.

${ }^{4}$ The attributes of gender of letter writer, year (and specific days) a letter exchange took place, and the city where the letter writer lived are clearly indicated in the Patri letter exchanges data files. Drawing from his experience analyzing the letters (LaRossa and Reitzes, 1993), Dr. LaRossa notes that the vast majority of letter writers refer to the gender and age of the child about whom they were writing. Dr. LaRossa also notes that, while there is little direct reference in the letters to socioeconomic status indicators (i.e., education, occupation, or income of letter writers), he and his co-researcher surmised that those who wrote to Patri generally were middle class (based on the quality of the stationery and grammar and spelling in the letters). Regarding the attribute of family structure, it is possible that this information could be gleaned from letter content as well. 